\title{
P-167
}

\section{DPPH Radical Scavenging Activity, Total Phenolics, and Antimicrobial Screening of Selected Pteridophytes}

\author{
Dorothy A. Antesa ${ }^{1, *}$ and Yasmin A. Griño ${ }^{2}$ \\ ${ }^{1}$ Natural Science-Math Depatment, Notre Dame of Marbel University, City of Koronadal, 9506, Philippines; ${ }^{2}$ Natural \\ Science-Math Depatment, Notre Dame of Marbel University, City of Koronadal, 9506, Philippines; \\ E-mail:dottieantesa@yahoo.com
}

\begin{abstract}
An enormous species of medicinal plants worldwide are traditionally used and in most cases no scientific studies have been done to prove their efficacy. This study was conducted to evaluate the folkloric therapeutic claims of ten selected Philippine medicinal pteridophytes by determining the phytochemical, antioxidant, and antibacterial activities of the leaf extracts. Qualitative screening of the phytochemicals showed that alkaloids, saponins, flavonoids, and tannins were present in their leaf extracts. (DPPH) free radical scavenging assay was used to determine the antioxidant activity. All of the extracts exhibited different extent of antioxidant activity. Among the plant samples tested, Blechnum orientale methanolic leaf extract had the greatest antioxidant activity while Lycopodium cernuum had the least. $\mathrm{The} \mathrm{IC}_{50}$ values ranged from $3.71 \mu \mathrm{g} / \mathrm{mL}$ to 32.37 $\mu \mathrm{g} / \mathrm{mL}$. The total phenolic content (TPC) of the leaf extracts showed large variations, between $77.44 \pm 0.37$ and $413.52 \pm 1.42$ $\mathrm{mg} \mathrm{GAE} / \mathrm{g}$ extract. The extracts arranged in decreasing values of TPC are B. orientale $>D$. linearis $>O$. pistillaris $>P$. vitatta $>$ N. biserrata $>D$. esculentum $>C$. contaminans $>A$. nidus $>L$. cernuum $>P$. scolopendria. TPC of the extracts is shown to be positively correlated with the antioxidant activity $\left(\mathrm{IC}_{50}\right)$. Antibacterial activity was evaluated using Kirby-Bauer method. Eight extracts inhibited the growth of Bacillus subtilis, seven inhibited Escherichia coli, four inhibited Pseudomonas aeruginosa, and six inhibited Staphylococcus aureus. These pteridophytes could be potential rich resources of natural antioxidants and could be developed into functional food or drug for prevention and treatment of diseases caused by oxidative stress.
\end{abstract}

Keywords: DPPH Radical Scavenging, Total Phenolic Content, Phytochemicals, Antimicrobial, Pteridophytes. 